\title{
Perceptions of policies and programs and their impact in supporting employment among individuals with spinal cord injury
}

\author{
Karla S. Reed ${ }^{\mathrm{a}, *}$, Michelle Meade ${ }^{\mathrm{b}}$, Melinda Jarnecke ${ }^{\mathrm{a}}$, Richard Aust ${ }^{\mathrm{a}}$ and James S. Krause ${ }^{\mathrm{a}}$ \\ ${ }^{a}$ College of Health Professions, Medical University of South Carolina, Charleston, SC, USA \\ ${ }^{\mathrm{b}}$ Physical Medicine and Rehabilitation, University of Michigan, Ann Arbor, MI, USA
}

Revised/Accepted October 2017

\begin{abstract}
.
BACKGROUND: Spinal cord injury (SCI) is associated with unacceptably high unemployment rates that are impacted by the environment in which employment and vocational activities take place. To improve employment outcomes, we must continue to gather data allowing us to evaluate the effectiveness of policies and programs associated with successful employment from the perspective of persons with disabling conditions.

OBJECTIVE: Identify key components of programs and federal and state level polices which support employment outcomes, as perceived by individuals with SCI who have worked since injury.

METHODS: Qualitative approach using six focus groups at two sites. All participants $(\mathrm{N}=44)$ had been employed at some point since injury. A semi-structured interview format asked questions about policies and program related factors influencing job attainment, maintenance, and advancement following SCI. Narratives were extracted into themes falling into the overlapping categories of policies, programs and awareness.

RESULTS: Within programs, five themes emerged characterizing components of programs perceived to be significant in supporting employment: (1) support for education, (2) development of job seeking skills, including skills assessment; (3) job placement; (4) practical experience, and (5) instrumental support. Within policies, two themes were extracted related to policies focused on individuals and policies focused on changing the environment. Finally, within the category of awareness, themes reflect the importance of personal connections and self-advocacy.

CONCLUSIONS: Policies and programs are not static factors but change and differ based on how they are understood, implemented, and reacted to in different places and by different groups. Researchers, program developers, and policy makers should consider how persons with SCI from diverse backgrounds and levels of impairment perceive and are supported by the varying programs and policies in their particular institution, region or state.
\end{abstract}

Keywords: Spinal cord injuries, employment, qualitative research

\section{Introduction}

Traumatic spinal cord injury (SCI) is a lifechanging event that typically results in severe and permanent physical disability, as well as reduced

\footnotetext{
*Address for correspondence: Karla S. Reed, MA, College of Health Professions, Medical University of South Carolina, 151-B Rutledge Ave, MSC 962, Charleston, SC 29425, USA. Tel.: +1 843 224 0597; E-mail: swayngim@ musc.edu.
}

participation in society and employment. Despite legislation aimed at improving employment outcomes after SCI, the employment rate of persons with SCI continues to fall well below that of the general population (Murphy \& Young, 2005; Ottomanelli \& Lind, 2009). Labor force participation is associated with higher earnings, better health, higher quality of life, and even greater life expectancy (Krause, Saunders, \& Acuna, 2012; Krause \& Terza, 2006; 
Lidal, Huynh, \& Biering-Sorensen, 2007; Meade, Reed, Saunders, \& Krause, 2015). Yet, persons with SCI face fewer opportunities, inadequate support and accommodations, and less social and political resources (Hammell, 2015; Jongbloed, Backman, Forwell, \& Carpenter, 2007). Improving the employment rate among persons with SCI is an important endeavor, which could be aided by the ongoing collection and analysis of data articulating the impact of existing policy and program components.

Programs such as vocational rehabilitation exist to assist those with disabling conditions with employment. Sadly, recent research has documented a "disproportionate decline" in vocational rehabilitation services for those with SCI (Schoen \& Leahy, 2012). This decrease in services almost certainly will widen the gap of employment outcomes between those with and without SCI. One study found that in those who received vocational rehabilitation services, $40 \%$ reported the services did not help at all, while only $24 \%$ reported that they helped significantly (Meade, Armstrong, Barrrett, Ellenbogen, \& Njeri Jackson, 2006). Furthermore, the decline in services likely will result in a decreased emphasis on the quality of employment outcomes, as compared with simply transition to employment (i.e., employment rates). While the transition to employment is a critical first step towards employment, it is important to also consider other quality indicators of employment, such as job satisfaction, extrinsic and intrinsic rewards, and opportunities for advancement (Hausknecht, Rodda, \& Howard, 2009). Recent research has found vocational services that not only provide job seeking and acquisition but also provide individual placement and on-the-job support are more likely to lead to employment rather than services that only provide transition to employment (Ottomanelli, Barnett, Goetz, \& Toscano, 2015). Several case studies have corroborated the benefits of this approach, illustrating the need to emphasize individual support and ongoing on-the-job support to help persons with SCI acquire and maintain employment (Inge, Wehman, Strobel, Powell, \& Todd, 1998; Targett \& Wehman, 2003).

The United States Department of Labor recommends policies to promote job retention and reemployment after onset of a disability (Hollenbeck, 2015). In that respect, policies such as the Americans with Disabilities Act (ADA), the Equal Employment Opportunity Act, and Employment First exist at the federal and state level to assist persons with disabilities in reducing barriers to employment and increasing the likelihood that they will enter and remain in the labor force. These policies are meant to benefit persons with SCI and other disabling conditions by providing reasonable accommodations, access to benefits, and privileges of employment (Somerville, Wilson, \& Bruyere, 2000), and research has shown such policies can be successful. For example, one study found a $20 \%$ increase in the likelihood of employment after SCI corresponded with the enactment of the ADA (Pflaum, McCollister, Strauss, Shavelle, \& DeVivo, 2006). Similarly, states which have implemented an Employment First policy have consistently shown increases in the number of people with disabilities who are employed (LEAD Center, 2016). Yet, in some instances, the policies themselves may be perceived as part of the barrier. For example, policies may systematically limit employment if health benefits are perceived as being jeopardized by working and earnings (Krause et al., 2012). Furthermore, awareness of rights is essential for programs and policies to be effective.

\subsection{Purpose}

Given the ongoing attempts to redefine and restructure policies and the pressures on the funding for programs that support individuals with SCI and other disabilities, it is important to continue to collect data about how these programs are used and perceived by those individuals. The objective of this study was to describe how programs and federal and state level policies are perceived to impact the employment of individuals with disabilities, as identified by individuals with SCI who have worked since injury.

\section{Methods}

\subsection{Participants}

Participants were identified through an ongoing longitudinal study of SCI initially conducted at rehabilitation hospitals in two states, Georgia (GA) and Minnesota (MN), as well as through a community resource in MN. Eligibility criteria included: (1) disability resulting from traumatic SCI, (2) minimum of 10 years post-injury, ensuring at least a decade of living with SCI from which to draw employment experiences, (3) worked at some time post-injury, although they may have been unemployed at the time of study. Six groups were conducted, three at each site (MN, GA), with 4 to 9 participants each $(\mathrm{N}=44)$. Table 1 summarizes participant characteristics. 
Table 1

Participant characteristics

\begin{tabular}{lc}
\hline Characteristic & \% or Mean (SD) \\
\hline Gender & 70 \\
Male & 30 \\
Female & \\
Race/Ethnicity & 83 \\
$\quad$ Non-Hispanic white & 23 \\
$\quad$ Minority & $52.2(10.05)$ \\
Current age (Range: 30 to 73 years old) & $21.57(9.76)$ \\
Age at injury (Range: $<1$ to 47 years old) & $30.66(2.83)$ \\
Time since injury (Range: 14 to 58 years old) & \\
Current work status & 50 \\
$\quad$ Working & 23 \\
$\quad$ Not working & 27 \\
Retired & \\
Level of injury & 11 \\
$\quad$ Cervical 1-4 & 37 \\
Cervical 5-8 & 45 \\
Thoracic & 7 \\
Lumbar & \\
\hline
\end{tabular}

\subsection{Data collection procedures}

Focus groups were conducted between April and September 2013. After receiving institutional review board approval, informed consent was obtained from each focus group participant. The focus groups were run by two facilitators, one who led the discussion and a second who took notes. A semi-structured interview format asked questions about personal, environmental, and policy related factors influencing job attainment, maintenance, and advancement following SCI. Participants were queried about the policies or programs that were relevant to obtaining or sustaining employment as well as if there were programs or policies that got in the way.

\subsection{Data analysis}

Groups were audio and video recorded and lasted between two to three hours. Professional transcriptions were obtained of the recordings, which group facilitators reviewed for errors. "Cleaned" transcripts were uploaded into NVivo10 qualitative software, a program designed to facilitate the processing and analysis of text-based documents. Two authors reviewed the transcripts multiple times before coding to identify topics, themes, and patterns.

\section{Results}

Participants shared their perceptions of various policies and programs as relevant to their employment. Results occurred within three overlapping categories. Analyses of program-related responses resulted in five themes, while analyses of policy-related responses resulted in two separate themes. A final category related to awareness was extracted from both topics (policies and programs), including themes associated with personal connections and self-advocacy. Given the length of the narrative, what follows is a cross-section of participant perspectives. Aliases are used for participant names.

\subsection{Themes related to programs}

Five themes were extracted from the focus group transcripts describing programs or program components participants felt impacted their ability to obtain or maintain employment after SCI: (1) support for education, (2) development of job seeking skills, including skills assessment, (3) job placement; (4) practical experience, and (5) instrumental support.

\subsubsection{Theme: Support for education}

Post-injury education is significantly associated with greater odds of employment (Krause \& Reed, 2009); therefore, it makes sense that participants identified programs supporting education post-injury as impacting their ability to become employed after SCI. For those injured at younger ages, programs at the elementary through high school level were helpful. For example, Milton, a male African American participant, stated,

The school I went to had a special-needs class. Of course, with me having a disability, being in a wheelchair and all, I went to all regular classes. But my homeroom had other students with disabilities. So there were all sorts of discussions, networking like Goodwill, a lot of networking things especially me being a senior in high school. I was only here for my junior and senior year of high school, so I was already prepared to know what you want to do. We had networks that you could get connected with.

Programs at the college level were also beneficial, as Pam explained:

So I started college, but [the Rehabilitation Hospital I went through] was very good about setting me up with the best places for handicapped student to go. Then they hooked me up with vocational rehab to help pay for some of that stuff and 
let me know what they could do for me in school. But the schools, since I was injured in' 89 and was going back to school in '91, I'm lucky because I got the benefit of where you all have been. Colleges were good for handicapped students, having dedicated people who would find note takers to make everything easier for you. That happened for me ...

Most commonly, these programs provided funding for individuals with SCI to attend postsecondary education. For example, Chester shared, "I took advantage of vocational rehabilitation and went back to school. They paid for school grants." Roy stated, "I used the same thing. I used vocational rehab to get back into school. They helped pay for stuff like that."

In some places, the programs not only provided funding for college but also paid for the personal assistance needed to attend. This then served as a motivator to continue education.

In [STATE NAME REMOVED], there was no $P C A$ program. Voc rehab said they would pay for a PCA for $\$ 500$ bucks a month if I'd go back to school. So I went to school not for any reason. After 3 years, I started doing computers and got a computer science degree in 1985.

\subsubsection{Theme: Job seeking skills, including skills assessments}

Assessment of skills and training in the skills needed to obtain employment were valuable to many participants. Vernon shared:

Vocational rehab, what they do is try to match your skills and education. Even if you don't have the educational background, they still try to match what skills with what you' re interested in doing with transfer and being able to see if you can adapt to the job you' re interested in.

Some participants indicated assistance in developing the skills needed to seek competitive employment, such as Pam's statement, "Then vocational rehab and the schools were good with the things students need like resume writing, the funding I got from GRS to help me get those tools and that education." Benjamin reported, "There was some training that voc rehab helped with, and that was doing resumes. When I got out of college, I didn't know how to do them; so I took a class for that."

A variation on this theme was the view that the assessment and assistance were not necessarily "good at finding out what you were good at" (Joanne) or had "a tendency to pigeonhole people" (Jeannette). Jeannette went on to explain:

Voc rehab does have a tendency to pigeonhole people. If you want to break out of that, you have to fight hard to do it. I was told early on that I could probably make a darned good receptionist. Not that it isn't a great position, but I was 17 and wasn't sure what I wanted to do with my life, and they were trying to guide me into ...

\subsubsection{Theme: Job placement}

Assistance with finding employment and job placement services were a key component this group identified as potentially important but only inconsistently available. Some participants were able to identify specific programs to assist them in connecting with jobs:

I went through Projects with Industry.... They found me a job in [CITY NAME REMOVED]. My friends I graduated with were getting jobs for $\$ 30,000$, and I finally found a job for $\$ 17,000$ through projects with disability with a higher GPA and a disability. Back in those days, it was different than today.

For other individuals, they were able to connect with vocational specialists through their rehabilitation center or program who were able to identify and connect them with job opportunities. Allen recalled a specific person who was particularly impactful:

But [name deleted] called me, because I let her know what was going on. And probably like a week they let me go because I told them I wasn't pursuing a criminal justice degree, she called; and I was introduced to [NAME DELETED], who was over Home Depot. They had a position there in their security department, so I was hired.

However, it did not seem as if specialized assistance for individuals with disabilities was always needed. Several individuals worked with general agencies who provided them with assistance.

Ronnie: An employment agency. That's how I got my first job. I heard them on the radio. I called in on the radio show. She gave me her number and said call; so about a month later, she had me this job.

Many of the participants, though, had expected to receive job placement services from vocational 
rehabilitation providers and found themselves disappointed when they did not.

Joshua: I found VR was helpful getting me back to school and through school, but when school ended, VR ended. They encouraged me to find a job because, if I found a job that helped them in [STATE] because they need numbers to support their success. The problem was they had no help for finding a job. That left that completely up to me.

Finally, other participants suggested vocational rehabilitation was willing to assist but was too slow for them and so they conducted their own search to find a position.

Milton: When I moved up here 2 years ago, when I moved to Atlanta, I used them to try to find a job. But like everyone was saying, they were so slow; they were taking me through the process of trying to find jobs that match me. I know what jobs that match. I have my masters in a field, but they still had me going through the long process. I just got on the computer myself and started searching for jobs because, by going through their process, it was just taking way too long.

As summarized by Vernon:

Personally, I have outgrown Voc Rehab. Once you get to that point where you've outgrown them, you can see other things you can start doing for yourself. Like right now everything is computer based now, and you can start looking for jobs on line. But if you're that person that needs that guidance or pointed in a direction, you can vocational rehab to your advantage.

\subsubsection{Theme: Practical experience}

Programs providing practical experience through on-the-job training have been shown as positively related to successful employment outcomes after SCI (Marini, Lee, Fong, Chapin, \& Romero, 2008). They help individuals gain comfort regarding employment, perhaps through volunteer activities and through greater awareness of opportunities and developing personal connections with others with disabilities. Narratives from the current participants bolstered this finding. Edmund recalled:

So he got me going through Goodwill. I went through the Goodwill program. I finished school, but I wanted to tighten my skills, so I went through the adult training at Goodwill for about six months, and Goodwill hired me as a receptionist.

Practical experience was also described in the form of internships or apprenticeships:

Allen: I was 17. I moved to Georgia in ' 94 and finished school, graduated in '96, and I also was employed when I graduated. I was part of an internship program, which I was being paid for, and I was working with Georgia Bureau of Investigation.

Allen further explained how an apprenticeship program aided in obtaining employment:

It was a three-month program, and they paid the \$300 stipend. Then the Department of Labor ended up taking over that pilot program where they would put you to work. Then if you worked out, they liked you, then they give you a full-time job.

Finally, Ronnie reiterated the positive side of internships leading to employment but also the downside to employer's abusing internships:

That's right. That's how I got the job to start with. It helps get you in the door. That way, you don't worry about hiring you, and paying you. It got to where a lot of these companies were just using you for free help for three months.

\subsubsection{Theme: Instrumental support}

Narratives reflected the importance of programs that provided instrumental resources and assistance. Within this theme, three different types of instrumental support were mentioned as impacting employment: assistive technology, including wheelchairs; transportation; and personal care assistance.

Assistive technology is essential for improving participation and employment outcomes of many persons with SCI as this category of devices includes "any item, piece of equipment, or product system... that is used to increase, maintain, or improve functional capabilities of individuals with disabilities" (The Assistive Technology Act, 2004, p. 1710). Richard shared his experience in receiving support for assistive technology through Vocational Rehabilitation and the Plan to Achieve Self-support (PASS) program:

I used Voc Rehab originally. They supplied me with computers and voice-recognition software 
and all that kind of stuff so I could go to school. Then when I found this PASS program through Social Security that was a much better deal. I used the Pass program to buy myself a vehicle and lots of good stuff.

The importance of having support for obtaining and maintaining wheelchairs was apparent in statements such as the following from Edmund:

And with an electric chair, it's like an automobile. It will go down on you when you least expect it. This was my first problem when I was working. I only had one chair, and when it went down, I had push chair, which, me being a quadriplegic, I wasn't able to push it too good even if I had somebody to come get me. So that was another problem.

In that respect, programs providing support for wheelchair maintenance were valuable. For example, Ronnie described:

Help you maintain it...I hooked up with a church called [NAME REMOVED] Christian Ministries. They came out and interviewed me to see my situation. Gave a check to agency I needed help from for \$2,000. So [NAME REMOVED] Christian Ministries was a major help because they helped me with medication and my life because I wanted to do little things at that time, so [NAME REMOVED] Christian Ministry helped me as well. So now I don't actually have two chairs. I have three chairs! So one go down, I can get in another chair.

Programs providing transportation or funding to purchase or adapt personal vehicles were critical to the employment pathway of many participants. The PASS program and its assistance in allowing one to save for an adapted van was already mentioned above by Richard. The following conversation provides more insight into this issue:

Eloise: After I started back work the last time in '86 I believe, I didn't become depressed, but I was having to depend on people at work to help me get in and out of my vehicle because I didn't have a van then. So I called vocational rehab and said, "What can you do help me?" "We can get you a lift." And I said, "What about a car?" and they said, "No, we can't get you the van, we can get you the lift." So I pursued that, and they helped me get a lift for a van. I had to buy the van. But that was like the load lifted that I needed totally. So they did help me with that part.

Raymond: Also they [Goodwill] would take care of a ride or provide transportation, they would take care of that. They would give you a MARTA card or van transportation. They would make sure you got there and make sure you got home. It was a great program to go through.

Sabrina: I use it [Metro Mobility paratransit system] on a regular basis and have for about 21 years. Efficiency and getting someplace on time if you' re not a planner, 60/40. To get to this meeting today, I left my house at 10:20 for a 12 o'clock meeting. Two other people on the bus and other issues. You have to think of the time of day you're traveling on the freeway coming from St. Paul. There are several people who have jobs who have standing orders like she does. Their only transportation is Metro Mobility. Even those who have those standing orders will sometimes get left at their job a half an hour or get there a half an hour late.

For many individuals with SCI - particularly those with high-level injuries - personal assistance services, whether performed by family members or paid caregivers, are necessary for accomplishing activities of daily living as well as more complex activities. Programs providing support for these services, then, were often critical in the employment process.

Allen: To maintain any job, paying or volunteering, it's about your drive but also it does start at home because in order for you to get out of your house every day, you do have to have someone dependable as far as a caretaker is concerned because, if something goes wrong (I got stories for days), it's a domino effect. ...And, as far as my caretaker is concerned, which I've been fortunate, but we're all human. People get sick, emergencies happen; so I do have two caretakers, and they're paid through a program.

When asked if any program helped pay for personal assistance, Ronnie responded:

There are none. The only one is a Medicaid waiver [ATTENDANT CARE MEDICAID WAIVER]. Right now, you can't buy an insurance policy that will cover morning and nighttime personal assistance, getting out of bed. The only way you're going to be able to do it is basically have your job that has... When I worked for the bank, they 
had a self-insured plan, which they can buy over and beyond what your policy states, a self-insured plan. But that's one of the problems why you can't people hired because they're afraid their insurance is going to go up, so they don't want to hire you.

\subsection{Themes related to policies}

Two themes were extracted into two broad areas policies focused on individuals and policies focused on changing the environment. Of note, many of these policies support or provide funding for the programs and program components mentioned above.

\subsubsection{Theme: Policies focused on individuals}

Our participants perceived policies as impacting individuals by (1) providing a safety net, but also (2) creating barriers and increasing fear.

\subsubsection{Subtheme: Provide a safety net. The finan-} cial ramifications of a significant disability are a major concern after SCI. Policies aimed at providing a safety net, covering medical expenses, and supporting financial independence were seen as important by participants. As Raymond stated:

I want to say this right here: I know they were saying about the financial thing, I know my bills were high when I went to the hospital, I had Medicare; but they would give Medicaid, and they would pay my bills. You would fill out these forms in the hospital, temporary Medicare, and they would pay the bills. They took care a lot of my bills.

Beyond healthcare costs, policies influenced the participants' ability to maintain a job through work incentives and increased earnings to the point of becoming financially independent, as Max explained:

Being able to use Social Security work incentives in a way that will provide some of that support at the job can be important in terms whether or not a person is able to maintain a job. ... So you can earn well above the substantial limit but still, because of the supports you need, have the safety net of Social Security while you work towards getting off Social Security benefits or maximizing your financial independence through using those work incentives.

3.2.1.2. Subtheme: Create barriers/increase fear. Many of the same policies seen as important for providing a safety net were also seen as having the potential to limit employment because of fears of being penalized or losing incentives. The wife of one participant (Brent) described how certain policies have affected his potential for employment by restricting access to health insurance and Medicaid:

During that time he was going through the disability, we weren't married. Now that we are married, he can't get Medicaid because my mother, who passed away, left land; and so they say I need to sell that land to pay for his doctor bills before they'll help us. It's been passed down, and I don't feel that's fair policy. I'm afraid for him to go to work anywhere because he doesn't have insurance. They call the ambulance so much. Where we live, if he needs to come to Atlanta, instead of calling the ambulance, they call the helicopter. It lands at our house.

Yukami explained how the fear of losing incentives must be taken into consideration when considering employment and the uncertainty of how certain programs work:

Right. For a lot of people, I wish there was something in between. It would be great if there were more of a trial period, because the fear of losing insurance is huge for people. And if you make $X$ amount of dollars, you're going to lose it; and that means, even if you make a buck or two more. So it's got to be an even trade-off.

Charlie echoed this sentiment:

I'm agreeing with her because you get a job and trying to get a job to better yourself, but the job you have you're not getting as much money as you should but you' re still getting your disability. But then you make a little bit more, then they cut it off. Then you lose your job, and then you got to go through the whole effort of getting the Social Security and going through a lot of trial and error.

\subsubsection{Theme: Policies focused on changing the environment}

Aside from impacting individuals, policies were also perceived to have a more broad impact on the environment. In particular, participants described these policies as (1) providing opportunities, (2) challenging discrimination, and (3) increasing accessibility. 
3.2.2.1. Subtheme: Providing opportunities. Some policies led to increased opportunities for people with SCI and other disabling conditions by way of providing work incentives and job accommodations, defining rights, and even changing the way people think about disabilities. The value of work incentives stood out to Max:

I believe that Social Security work incentives are huge in terms of people going back to work, especially people transitioning from a non-skilled position into a skilled position where they have that opportunity to use those work incentives over time to get into the workplace.

Specific to job accommodations, Yukami felt opportunities were improved by companies working to improve the work environment, "A little of both because I see people going back to work all the time, and I've seen some companies go backwards to make sure their former employee will be in a safe environment." Bill also viewed policies on accommodations as supporting his return to work:

For me, reasonable accommodation, particularly in traveling, I probably can figure a way to travel and be responsible for compensating the person who travels with me because, with my limitations, I always had to have someone travel with me. But because of reasonable accommodations policy or law, my employer paidfor someone to travel with me.

Nicolas viewed the increase in opportunities as related to policies defining rights:

I think about in the Americans with Disabilities Act, is amazing. I remember not being able to do tons of stuff. I couldn't go to public school! They shipped me away to crippled children's school. It's a whole different place now. You have rights toward employment, rights written in the law, so you can pursue a lot of opportunities.

Bill felt doors were opened by policies leading to changes in attitudes:

More than policies has been attitudes of people involved in rehabilitation and the attitudes of employers. Fortunately, I came along at a time when there was more emphasis on employers providing people with disabilities equal opportunity. There was Title IV and the ' 73 Rehab Act, which was not the strongest law; but that and the attitude began to help change attitudes to get people to look at their own attitude. Even though there's a downside to the study, people would hear about disabled people making better [employees], so there was an upside that probably opened some doors.

\subsubsection{Subtheme: Challenging discrimination.}

With the passing of policies to improve outcomes after disability, participants saw decreases in discrimination, as noted by Yukami:

Employment is a little different now than 10 or 15 years ago because people are savvier about the different kind of disability so to lump everybody into one doesn't work. Employers are a lot more responsive. Plus, as Collin said, ADA is the law of the land.

Jeffrey described how policies against discrimination helped him in the workplace:

My boss, who is no longer there, was discriminating; so I went to the EEOC about it. They investigated and found out things that went on at my job that he did that wasn't right. ... I already had my job; but when they investigated, they found out. I wasn't trying to go for the money; I just wanted to work without being harassed. They got rid of him, and I got his job.

Max discussed how persons with disabilities need to understand that the goal of policies such as the ADA is not necessarily to guarantee employment but to guarantee against discrimination:

For most employers I have worked with over the last 20 years or so, in terms of hiring an employee with a disability, it's not about how much it's going to cost to make accommodations or the tax credit. It's always been about are we getting a qualified individual to do this job. As someone mentioned, just because you're a person with a disability doesn't mean you're the best employee for the program. The ADA doesn't state that. A lot of individuals with disabilities think the ADA is going to guarantee them a job. It just guarantees you can' t be discriminated against because of the disability.

3.2.2.3. Subtheme: Increasing accessibility. Employment has been impacted by policies leading to increased accessibility. According to Charlie: 
And like I was saying before, I got hurt in the late 80 s. Trying to get a job back then was more difficult than now because you had ADA but a lot of things weren't being done like [MASS TRANSIT SYSTEM]. If you wanted to catch a bus back then, if the bus came that didn't have a lift, you had to wait for the next bus to come that had a lift. Now all busses have the lift. Or the elevator might not be working, so you got to wait for them to fix the elevator. Then you' re late for the interview; and they figure if you're going to be late for the interview, you already in a wheelchair, he's going to be late all the time. They don't take into consideration certain things.

Joanne shared how her company provided accommodations, "When I started back to work, there was a person in the company who assessed your work environment and made it accessible for you." Finally, Arlene described how sometimes change was not always easy but it was necessary and beneficial:

Anyway, we keep going on. I' d like to mention the tremendous change in accessibility over the many years I've been working. Sometimes changes to accommodate people were made relatively easily and not too much work was really involved. And sometimes it was made a major deal, which I don't think was necessary.

\subsection{Awareness}

Awareness of the policies impacting individuals with disabilities and the programs that may be available to support or assistant them varied widely between participants in our focus groups. For this reason, it was extracted as a separate category with two themes: (1) Awareness and Personal Connections; and (2) Awareness and Self-Advocacy.

\subsubsection{Theme: Awareness and personal connections}

Significant differences in awareness of the policies and programs appeared to exist between participants in our focus groups based, in part, on where and when their rehabilitation occurred, their personal networks, and involvement with the disability community. Benjamin explained:

Well they had this program called 1619B, but nobody knew about it back then. This was ' 85 . I never heard of it back then. It was on the books; but Social Security never brought that up to me. So I am working, and the more money I make, the less I make. It started making think working isn't such a good deal even though I like to be busy. I thought I was losing money. I' $m$ a little bit of a slow thinker.

The importance of being proactive in learning about and how to use programs was also apparent. Nicolas shared, "The Social Security administration doesn't bend over backwards to make it all clear and easy to navigate that stuff. They're not about that. They're like 'This is all you get. We won't talk about it."”

Jeffrey: If you go to the Social Security website, it's a sea of information. It seemed like I got pointed in one direction; and sometimes after the fact, it's like, "Oh, you should have done this or that." It would be so nice if there was something where everybody was spelled out. In my mind, I needed a human being sitting in front of me that knew everything. Somebody who had been through the system that would educate you.

Many participants benefited from connecting with people who worked in the programs and networking with peers who knew the system. As Chester shared:

But it was the connection and relationship with these individuals that made them believe in me to go forth and do your thing. So networking is really important whether they had support from public programs or whatever.

Richard spoke about the value of networking with peers:

It goes back to networking. Bringing this group together is maybe beneficial to [STATE] and helps some folks younger to find their way. But I think it's important for all of us to stay networked as well with what we' re doing. There's a whole lot of information at this table. One of us knows something about it.

\subsubsection{Theme: Self-advocacy}

Several participants stressed the importance of knowing your rights and self-advocating when it comes to employment. According to Ronnie, "Only thing is rights. You need to know your rights." Yukami described how self-advocacy is so important when considering the diverse needs of people with SCI:

One thing that's important for all of us who are looking for employment is to be a self-advocate because my needs are going to be different than 
someone else's. Even though we are all categorized as somebody with a spinal-cord injury, self-advocacy is one of the most important things. You can do it in a nice way where people will want to help you. It depends on your tone and body language. It's one of those things we have to be conscientious of.

Victoria described a situation in which she had to self-advocate:

When I was at the University of [NAME REMOVED], which is extremely hilly, they had a van program that could drop you off at your classes. When I started working in Atlanta, you can imagine the parking situation; so I looked up their accommodation policy. I talked to them, and they paid for me to park across the street until I was promoted and got the good parking. But I advocated, pulled the policy, took it to the next step, and did it appropriately. They thought I would be a good employee, so let's try to work it out.

Finally, Max explained how the simple existence of a policy does not mean needs will automatically be met unless self-advocacy occurs:

I was injured in 1981. The rehab act was already kind of a policy. ADA came along a little bit later. Inever experienced any discrimination from employers or community. What I did notice was that if there was something I wanted to do somewhere that was inaccessible, that it was not up to some policy to bring that to the attention of the employer or manager. It was up to me to mention that. Because of people with disabilities, along the time of the mid-'70 s, early' 80 , making themselves more visible and raising voices individually and collectively is what brought about a lot of the policies that people who had disabilities later are benefiting from.

\section{Discussion}

Obtaining and maintaining employment following SCI is a complex and nuanced activity resulting from the performance of active, job-related behaviors by an individual within a given environment. The International Classification of Functioning, Disability, and Health model (WHO, 2001) includes policies and programs among the environmental factors influencing the functional outcomes (or level of disability) an individual achieves. Results of this study highlight how specific policies and key components of programs are seen, by the individual with SCI, as enhancing the ability to either obtain or maintain employment given their injury and personal characteristics.

Participants in this study perceived policies as having the potential to both benefit and limit their overall functioning. In particular, policies aimed at the individual were appreciated as a safety net that could also trap. More clear-cut was the role of policies aimed at the environment and providing opportunities. Participants appeared to have a unique understanding of history and the civil rights implications of policies such as the ADA. In part, this understanding seems to result from the age and background of participants as well as where they were recruited. Given that the time since injury ranged from 14 to 58 years $(\mathrm{avg}=30.6$ years) at the time of the focus groups, the majority of participants had lived with their SCI prior to the ADA, which also influenced the conversation. Furthermore, rehabilitation centers seem to imbed that sense of history to greater or lesser extents within their programming.

In terms of program components, funding postsecondary education, facilitating the development of job seeking skills, assisting with job placement, offering practical experience through internships and on-the-job training, and providing instrumental support were important in allowing individuals to engage in employment. Most of these components have been identified in previous research as vital in promoting employment for many groups, and elements of these programs are familiar not just within federal and state programs for individuals with disabilities but also in programs designed for the general population. For example, federal and state funding exists for postsecondary education (e.g., federal pell grants), and the School-to-Work Opportunities Act of 1994 acknowledged the need for schools to provide work-based learning components, such as workforce readiness training, technical preparation, and work experiences (School-to-Work Opportunities Act, 1994). Within various types of programs, certain functions were considered particularly important. The Department of Vocational Rehabilitation has been crucial in providing pre-employment training, skills assessment, job placement assistance, and financial assistance in the areas of assistive technology (voice recognition software, adaptive equipment for personal vehicles) and post-secondary education. The Social Security Administration (SSA) has a variety of programs 
designed to assist people with getting back to work and keep some or all of their disability benefits. Accessing a benefits specialist is essential to understanding how working affects a person's disability benefits and understanding how to use SSA services such as PASS and trial work periods. Without a benefits specialist, individuals may be unaware of a program that could help them return to or maintain employment. Regarding instrumental support, adaptive public transportation is an effective way to secure transportation for employment, and programs providing transportation assistance are critical in maintaining employment. However, even when adaptive public transportation is available and generally effective, there are many practical limitations in its use, such as scheduling and long transportation times that may be particularly difficult for those with severe disability resulting from SCI.

One of the most important findings was the range of awareness among participants. That is, individual awareness was often a necessary precursor to being able to identify, access, and benefit from the relevant programs or policies. Evident in the responses was how the location of the participant's inpatient rehabilitation experience affected their awareness and perception of various policies and programs.

Finally, self-advocacy is essential for people trying to access services. Understanding what is needed and how to navigate various programs will significantly improve outcomes. Programs and policies exist, but they require the person with the disability to be actively involved in following up on their recommendations.

\subsection{Implications}

Policies that mandate accessibility and challenge discrimination provide opportunities for individuals with SCI to function more optimally in all environments and roles. However, while participants were clear in indicating the importance of policies providing safety nets, they also indicated barriers related to policies and areas of confusion. Researchers, program developers, and policy makers should consider the areas of need addressed by these policies, awareness of them, and if they are sufficient to address the concerns of individuals with diverse backgrounds and levels of impairment.

The program components identified as critical to individual success appear to support continued prioritization of vocational rehabilitation departments and services. They reflect the diversity of needs that, if met, may dramatically improve employment prospects. Beyond education, the findings emphasize other important needs, which may be less costly, yet very important for ultimate success. Developing jobseeking skills may be overlooked in those who obtain significant retraining. It is one thing to be qualified for a job, but yet another to be able to find employment. Proper assessment and development of overall skills will reduce the likelihood of "pigeonholing" an individual just for the sake of getting them into any job. Furthermore, the findings demonstrate the need for placement and practical experiences, which may be underemphasized in current rehabilitation programs. Lastly, people need resources. Having the proper technology, transportation, and personal care assistants are all necessary components to obtain and maintain employment. Without the necessary supports, simply educating individuals will not improve the employment rate or the quality of employment outcomes.

Finally, results from this study highlight the issues of awareness and self-advocacy. In some ways, awareness may be the easiest of the findings to address and translate into actionable behaviors. While policies and programs supporting individuals with SCI and other disabilities are present, too many people do not know about them or cannot make sense of them. Additional attention should be directed at formatting and distributing the information and then ensuring that it is heard, understood, and implemented. Rehabilitation centers and other organizations providing care and services to individuals with SCI should continue to assist in providing information and connections to specific policies and programs that may be supportive of employment.

\subsection{Methodological considerations}

Qualitative studies have inherent strengths and limitations. The greatest strength is that it brings out ideas from the perspectives of those upon whom the study focuses. This was a clear strength in that it led to identification of several important support services individuals feel are necessary for obtaining and/or sustaining employment. These themes must now be operationalized and validated within more quantitative research designs.

In terms of limitations, qualitative studies typically have relatively small sample sizes, as was the case in the current study. Many participants were older, allowing us to identify themes occurring over many years but may be somewhat less reflective of 
experiences of individuals with more recent SCI. Furthermore, qualitative designs must go hand-in-hand with quantitative studies. The themes observed might have varying degrees of generalizability within the broader population of people with SCI. They may also have regional qualities, with variations by state, and other important themes may not have emerged based on the small sample size and geographic distribution of participants.

\subsection{Future research}

The question now is how can we use this particular information to advance the field and continue to develop interventions that will enhance employment and overall functioning for individuals with SCI and other disabilities? Possible steps include more systematic tracking of awareness, access, and outcomes for each. Small-scale studies comparing the effectiveness of varying forms of employmentrelated interventions, possibly tailored to particular needs of individuals, may also influence how general principles are translated effectively. One thing is clear though, it is only through systematic investigation that we will be able to build upon the current findings and maximize their utility in promoting employment outcomes among those with SCI.

\section{Acknowledgments}

The contents of this publication were developed under grants from the National Institute on Disability, Independent Living, and Rehabilitation Research (NIDILRR grant numbers 90RT5035, 90DP0050). NIDILRR is a Center within the Administration for Community Living (ACL), Department of Health and Human Services (HHS). The contents of this publication do not necessarily represent the policy of NIDILRR, ACL, HHS, and you should not assume endorsement by the Federal Government.

\section{Conflict of interest}

The authors have no conflict of interest to disclose.

\section{References}

Hammell, K. W. (2015). Quality of life, participation and occupational rights: A capabilities perspective. Australian Occupational Therapy Journal, 62, 78-85. doi: 10.1111/14401630.12183
Hausknecht, J. P., Rodda, J., \& Howard, M. J. (2009). Targeted employee retention, performance-based and jobrelated differences in reported reasons for staying. Human Resource Management, 48(2), 269-288. doi: 10.1002/hrm. 20279

Hollenbeck, K. (2015). Promoting retention or reemployment of workers after a significant injury or illness. Washington, DC: Mathematic Policy Research.

Inge, K. J., Wehman, P., Strobel, W., Powell, D., \& Todd, J. (1998). Supported employment and assistive technology for persons with spinal cord injury: Three illustrations of successful work supports. Journal of Vocational Rehabilitation, 10, 141-152. doi: 10.1016/S1052-2263(98)00010-5

Jongbloed, L., Backman, C., Forwell, S. J., \& Carpenter, C. (2007). Employment after spinal cord injury: The impact of government policies in Canada. Work, 29, 145-154.

Krause, J. S., \& Reed, K. S. (2009). Obtaining employment after spinal cord injury: Relationship with pre- and post-injury education. Rehabilitation Counseling Bulletin, 53, 27-33. doi: doi: $10.1177 / 0034355208329443$

Krause, J. S., Saunders, L. L., \& Acuna, J. (2012). Gainful employment and risk of mortality after spinal cord injury: Effects beyond that of demographic, injury and socioeconomic factors. Spinal Cord, 50, 784-788. doi: 10.1038/sc.2012.49

Krause, J. S., \& Terza, J. V. (2006). Injury and demographic factors predictive of disparities in earnings after spinal cord injury. Archives of Physical and Medical Rehabilitation, 87, 13181326. doi: 10.1016/j.apmr.2006.07.254

LEAD Center. (2016). Employment First: State Profiles. Retrieved from http://employmentfirst.leadcenter.org/states-profiles

Lidal, I. B., Huynh, T. K., \& Biering-Sorensen, F. (2007). Return to work following spinal cord injury: A review. Disability and Rehabilitation, 29, 1341-1375. doi: 10.1080/ 09638280701320839

Marini, I., Lee, G. K., Fong, C., Chapin, M. H., \& Romero, M. G. (2008). Vocational rehabilitation service patterns related to successful competitive employment outcomes of persons with spinal cord injury. Journal of Vocational Rehabilitation, 28, $1-13$.

Meade, M. A., Armstrong, A. J., Barrrett, K., Ellenbogen, P. S., \& Njeri Jackson, M. (2006). Vocational rehabilitation services for individuals with spinal cord injury. Journal of Vocational Rehabilitation, 25, 3-11.

Meade, M. A., Reed, K. S., Saunders, L. L., \& Krause, J. S. (2015). It's all of the above: Benefits of working for individuals with spinal cord injury. Topics in Spinal Cord Injury Rehabilitation, 21, 1-9. doi: 10.1310/sci2101-1

Murphy, G. C., \& Young, A. E. (2005). Employment participation following spinal cord injury: Relation to selected participant demographic, injury and psychological characteristics. Disability and Rehabilitation, 27, 1297-1306. doi: 10.1080/09638280500164644

Ottomanelli, L., Barnett, S. D., Goetz, L. L., \& Toscano, R. (2015). Vocational rehabilitation in spinal cord injury: What vocational service activities are associated with employment program outcome? Topics in Spinal Cord Injury Rehabilitation, 21, 31-39. doi: 10.1310/sci2101-31

Ottomanelli, L., \& Lind, L. (2009). Review of critical factors related to employment after spinal cord injury: Implications for research and vocational services. Journal of Spinal Cord Medicine, 32, 503-531. doi: 10.1080/10790268.2009. 11754553 
Pflaum, C., McCollister, G., Strauss, D. J., Shavelle, R. M., \& DeVivo, M. J. (2006). Worklife after traumatic spinal cord injury. Journal of Spinal Cord Medicine, 29, 377-386. doi: 10.1080/10790268.2006.11753886

Schoen, B. A., \& Leahy, M. J. (2012). An analysis of changing demographics of individuals with spinal cord injury who received state vocational rehabilitation services between 2004 and 2008. Journal of Rehabilitation, 78(3), 11-19.
Somerville, N., Wilson, D. J., \& Bruyere, S. M. (2000). Employing and accomodating individuals with spinal cord injuries. Ithaca, NY: Cornell University.

Targett, P., \& Wehman, P. (2003). Successful work supports for persons with spinal cord injury. SCI Psychosocial Process, 16(1), 6-11.

The Assistive Technology Act of 2004, Pub. L. No. 108-364, 118 Stat. 1707-1737 (2004). 